\title{
FUNDAMENTOS DEL BIODERECHO Y LA BIOJURÍDICA DESDE LA BIOÉTICA Y LA FILOSOFÍA DEL DERECHO
}

\section{FUNDAMENTALS OF BIODERECH AND BIOJURIDICS FROM BIOETHICS AND THE PHILOSOPHY OF LAW}

\begin{abstract}
José Jesús Albert Márquez, Ph. D. Doctor en Derecho (España).

Profesor investigador de la Filosofía del Derecho y Secretario académico de la Facultad de Derecho y Ciencias Empresariales y E.E de la Universidad de Córdoba, España.

ji1almaj@uco.es
\end{abstract}

\section{ARTÍCULO DE REFLEXIÓN}

Recibido: 31 de julio de 2018.

Aceptado: 28 de octubre de 2018.

\section{RESUMEN}

Los avances producidos en la ciencia y en la técnica en las últimas décadas han propiciado, en el campo de la medicina y sus disciplinas afines, la posibilidad de aplicar técnicas instrumentales capaces de transformar hasta el propio concepto de persona. Esto ha hecho necesaria una reflexión ética sobre la fundamentación y los límites de la implementación de estas técnicas, lo que ha dado lugar a la llamada bioética, entendida como una reflexión ética sobre las ciencias de la vida y la salud. A su vez, esta realidad reclama la necesariedad de normas jurídicas que la disciplinen, cobrando especial relevancia en este ámbito el bioderecho y la reflexión crítica que realiza la bioética. Por ello se hace particularmente necesario fundamentar correctamente ambas disciplinas, la bioética y el bioderecho. En todo este proceso, adquiere especial relevancia la filosofía del derecho como disciplina valorativa.

Palabras clave: bioética, bioderecho, biojurídica, dignidad humana, derechos humanos.

\section{ABSTRACT}

The advances made in science and technology in recent decades have led, in the field of medicine and its related disciplines, the possibility of applying instrumental techniques capable of transforming even the very concept of person. This made necessary an ethical reflection on the foundation and limits of the implementation of these techniques, which has led to the socalled bioethics, understood as an ethical reflection on the life sciences and health. At the same time, this reality demands the necessity of legal norms that discipline it, with the bio-law 
and the critical reflection carried out by bioethics taking on special relevance in this area. Therefore, it is particularly necessary to properly base both disciplines, bioethics and biolaw. Throughout this process, the philosophy of law as a valuation discipline acquires special relevance.

Keywords: Bioethics, biolaw, biolaw, human dignity, human rights.

\section{INTRODUCCIÓN}

Es probable que los avances producidos en las últimas décadas en los campos de la técnica y de la ciencia no sean comparables, ni cualitativa, ni cuantitativamente, con ningunos otros acaecidos hasta ahora en la historia de la humanidad. Como escribía Junquera de Estéfani desde los presocráticos y su búsqueda del principio vital, hasta los Vicenzo Abate, Mary Claire King, Jean Dausset, Patrick Steptoe, Robert Edwards, los "niños probeta", el ADN y el desciframiento del código genético, han pasado muchos siglos y, consecuentemente, los intereses y las posibilidades de investigación y experimentación son radicalmente distintos.

La medicina, por ejemplo, ha evolucionado más durante los últimos cincuenta años que en los últimos cincuenta siglos. Se sostiene así (Bernard, 1994, p. 7) que en estos años han tenido lugar dos revoluciones. La primera, la revolución terapéutica, comienza en 1936 con el descubrimiento de las sulfamidas y continua con los antibióticos. La segunda, la revolución biológica, inspiró el concepto de patología molecular que preside hoy día toda la medicina, y viene marcada por el descubrimiento del código genético, el descubrimiento de las leyes que rigen la formación de la vida.

Así, en el último cuarto del pasado siglo, se habla ya de una tercera ola en la historia de la biología en la que se abandona el progresivo estudio y conocimiento de los seres vivos, para dar un paso hacia el conocimiento de las estructuras últimas de la vida y comenzar a manipular y dirigir sus bases biológicas. En los años cincuenta del siglo pasado se dudaba todavía si el hombre poseía 46 o 48 cromosomas y hoy se está ya en disposición de sintetizar genes y trazar mapas cromosómicos (Junquera de Estéfani, 1998, p. 11). Se han perfeccionado, igualmente, técnicas de manipulación y conservación del material genético humano que posibilitan, entre otras, la fecundación in vitro, la gestación por sustitución, la selección de sexo, la reconstrucción o fabricación de órganos y hasta la clonación humana.

De hecho, se habla de "tecnociencia" para describir una situación en la cual los límites entre los conceptos tradicionales de ciencia y técnica se han diluido considerablemente (Aparisi, 2004, p. 68). Ejemplo de ello lo constituye el ámbito de la ingeniería genética, con especies 
transgénicas, tanto vegetales como animales. Lo anterior conlleva además dos efectos importantes: por una parte se hace evidente la inaceptabilidad de la tesis moderna de la neutralidad o asepsia valorativa de la ciencia, que en definitiva, depende de decisiones humanas que reposan sobre una ideología; por otra parte, las actuales ciencias experimentales no se dedican, pasivamente, al estudio y profundización en el conocimiento sobre el fenómeno global de la vida, sino que gran parte de su esfuerzo se dirige, fundamentalmente, a intervenir activamente en ella (Aparisi, 2004, p. 66-67). En palabras de Hans Jonas, el hombre se ha convertido en objeto de su propia técnica y hasta se puede afirmar que estamos en disposición de transformarnos a nosotros mismos (Jonas, 1994, p.35).

Y es que, como recuerda José Justo Megías, con frecuencia pensamos que toda evolución de la situación humana y de la relación entre el ser humano y su entorno natural es -y ha sidosiempre a mejor (Megías, 2009, p. 47). Por ello suele con frecuencia establecerse una correlación entre revolución y progreso, como si éste, siempre o al menos en buen número de ocasiones, fuera consecuencia de aquella. Habría también que concretar a qué tipo de progreso nos referimos, ¿científico, técnico, moral? El ideal sería que simultánea y armónicamente se diera en los tres aspectos, partiendo de la moral, pero lamentablemente la praxis demuestra las dificultades existentes para alcanzarlo (Porras del Corral, 2009, p. 21).

En suma, coincidimos con Diego Medina cuando estima que la postmodernidad nos ha legado a un hombre incapaz de saber que "debe" o que "no debe" hacer, un hombre desorientado por tanta y tan supuesta "sabiduría" o, incluso, un hombre cegado de soberbia, que, ante una ciencia que avanza, no es capaz de aceptar humildemente que todo descubrimiento puede estar al servicio del bien o del mal (Medina, 2009, p. 10). Más aún en tiempos donde el relativismo ha desdicho la doctrina del valor objetivo, la creencia de que ciertas actitudes son realmente verdaderas y otras son realmente falsas con respecto a lo que es el universo y a qué somos nosotros. En una época en la que se educa a las nuevas generaciones bajo estos parámetros de relativismo extremo, en la que, como escribía C.S. Lewis, "extirpamos el órgano y exigimos la función. Hacemos hombres sin nada en el pecho y esperamos de ellos virtud e iniciativa. Nos reímos del honor y nos sorprendemos de que haya traidores entre nosotros. Castramos y exigimos a los castrados que tengan prole" (Lewis, 2016, p.37).

En otras palabras, se precisa un refuerzo de la ética ante situaciones que sobrepasan la capacidad de juicio moral del hombre común de la modernidad y, además, se hace igualmente necesaria la intervención del derecho para regular, coactivamente si es preciso estas nuevas realidades. No hay que olvidar, además, que, en un mundo por completo globalizado, las legislaciones nacionales o regionales tienen una eficacia relativa para normar hechos que 
pueden realizarse en unos determinados países pero que tendrán sus efectos jurídicos en otros distintos. Piénsese en los problemas de la gestación por sustitución internacional, o del "turismo" genético en búsqueda de determinadas técnicas reproductivas.

El problema de fondo surge, a nuestro juicio, y como ocurre cuando se teoriza sobre los derechos humanos, cuando se plantea la necesidad (o no) de fundamentar qué ética y qué bioderecho consideramos los adecuados.

\section{REVISIÓN TEÓRICA}

\subsection{Bioética y bioderecho.}

\subsubsection{Orígenes y evolución de la bioética y el bioderecho.}

Los términos "bioética" y "bioderecho" (e igualmente "biojurídica", como veremos más adelante) constituyen neologismos cuya denominación terminológica, significado, contenido y no son pacíficos entre la doctrina.

En primer lugar, conviene precisar que una cosa es que los términos antedichos constituyan neologismos, y otra que antes de ser adoptados como tales, autores anteriores hubiesen realizado importantes desarrollos conceptuales sobre los principios y exigencias éticas que corresponden a las intervenciones del hombre en la vida humana. Ni mucho menos, que tales principios o exigencias no resultasen anteriores a sus conceptualizaciones científicas (Morelli, 2010, p.197).

En cualquier caso, se puede observar una prelación temporal entre bioética y bioderecho, en el sentido de que, como se verá, surgió primero la que ahora se denomina bioética, y ulteriormente el bioderecho o biojurídica, como respuesta o reflejo de la bioética en el campo del derecho. Se podría anticipar con carácter general que el bioderecho es la manifestación jurídica de la bioética (Schaefer, 2017, p. 286).

Por otra parte, se cuestiona la relación entre ambas disciplinas y su autonomía respecto de la ética y el derecho respectivamente, si bien se reconoce su carácter necesariamente multidisciplinar.

Es ya un lugar común en la literatura especializada señalar que el nacimiento de la bioética se debe a dos médicos, holandeses, cuyas especialidades médicas se ubican junto al inicio y al final de la vida humana: el fisiólogo de la embriología André Hellegers y el oncólogo Van Reselaer Potter, ambos catedráticos e investigadores. Potter planteó la bioética, literalmente, como un puente entre la ciencia (en torno a la vida y al medio ambiente) y el humanismo (en torno a la ética), y en un sentido global y más amplio que el que hoy normalmente se entiende 
cuando se alude a la bioética, pues en la obra de Potter, ésta comprendía no solo los actos del hombre sobre la vida humana, sino también sobre la vida animal y el medio ambiente en general. Se trataba, pues, de advertir sobre la necesidad de aplicar el saber biológico al mejoramiento de la vida (Morelli, 2010, p. 198).

En 1970, Van Potter publicó un artículo titulado Bioethics; the Science of Survaival, y al año siguiente publica su libro Bioethics: Brigde to the future, en el que recoge varios artículos. La propuesta de Hellegers, sin embargo, no coincidía exactamente con la de Potter, pues aquel no concibe la bioética como una nueva disciplina, sino como una rama de la ética clásica aplicada a las ciencias de la vida con el fin de resolver concretos problemas morales en el campo biomédico a través de la aplicación válida de principios éticos ya existentes y universales (Ciccione, 2006, p. 16)

En cualquier caso, la fórmula hizo fortuna rápidamente. A finales de los años 80 del pasado siglo aparece una etapa nueva que Potter denominó "Bioética global", pues se sistematizan las ideas referentes a la construcción de un nuevo "puente" entre la ética médica y la ética medioambiental. Por último, en los 90 surgió la denominada "bioética profunda" que es aquella que explora los nexos que existen entre los genes y la conducta ética, al entenderse que con el capitalismo los puentes entre los conocimientos empíricos de las ciencias naturales y sociales ya no eran suficientes para garantizar la supervivencia (García Fernández, 2005, p. 205).

La Bioética surge pues como un renovado esfuerzo de aplicación práctica de la ética y de la moral a las situaciones emergentes en el campo de las ciencias de la salud (González, 2004, p. 24).

Hoy día es pacífica la definición de bioética realizada en la Encyclopedia of Bioethics, (editada por W.T. Warren bajo el amparo del Kennedy Institute de Nueva York en 1995) que la conceptúa como el "estudio sistemático de la conducta humana en el campo de las ciencias de la vida y de la salud, examinada a la luz de los valores y principios morales" (Ciccione, 2006, p. 25).

No tiene el moderno bioderecho una fecha y lugar de nacimiento tan determinado como ocurre en el caso de la bioética. Tampoco goza de una paternidad definida con nombre y apellidos. Sin perjuicio de que inmediatamente después de la segunda guerra mundial se promulgó el denominado Código de Nuremberg (1947) como reacción a las atrocidades cometidas por los nacionalsocialistas durante la conflagración, y de que éste fue seguido por la llamada Declaración de Helsinki -ambos documentos se refieren a la experimentación con seres 
humanos- de 1964 (no se trata de un documento de derecho internacional, sino de una propuesta de la Asociación Médica Mundial -AMA- que tiene carácter privado), lo cierto es que a partir de los años 70 del pasado siglo, y sobre todo de los 80 , cuando empieza a surgir un amplio cuerpo normativo (en su mayor parte encuadrable en lo que se ha llamado soft law) que podemos amparar bajo el nombre de bioderecho, entendido genéricamente como el estudio de los aspectos jurídicos de las mismas temáticas abordadas por la bioética: el comienzo de la persona humana, la protección de la dignidad personal frente al avance tecnológico y biomédico, la procreación, la relación sanitaria, el morir, etc. (Morelli, 2010, p.201).

La referida Declaración de Helsinki de 1964 fue actualizada en 1975, 1983, 1989, 1996, 2000 , 2002, 2004, 2008, y 2013 en sucesivas Asambleas Generales de la AMA, lo cual es indicativo de la importancia de la propia Declaración y de la continua evolución de las técnicas científicas. Además, cabe citar la Declaración sobre los derechos de los pacientes, adoptada por la Asociación Americana de Hospitales en 1973, o la Declaración de Lisboa de 1980, aprobada por la Asamblea de la AMA, que indica la posición de la profesión médica.

En el ámbito europeo, es de destacar la preocupación sobre estos temas (al igual que en el ámbito de la protección de los derechos humanos) que desde un primer momento mostró el Consejo de Europa (mérito no extensible a la antigua Comunidad Económica Europa, actual Unión Europea) al crear en 1985 el Comité de Expertos para los problemas de la Bioética, luego denominado Comité Director para la Bioética. En 1991 se creó el Grupo europeo para la ética de las ciencias y las nuevas tecnologías. Así mismo, el Consejo de Europa propició la promulgación de Convenio de Oviedo (Convenio para la protección de los Derechos Humanos y la Dignidad del Ser Humano con respecto a las aplicaciones de la Biología y la Medicina) el 4 de abril de 1997.

También en el seno de Naciones Unidas se ha ido creando un cuerpo normativo especial desde que en 1993 la Unesco creara el Comité Internacional de Bioética, que dio lugar a una serie de importantes documentos: en 1997 la Declaración Universal sobre el Genoma Humano y los Derechos Humanos; en 2003, la Declaración Internacional sobre los Datos Genéticos Humanos, y en 2005, la Declaración Universal sobre Bioética y Derechos Humanos. Con un nivel algo menor de compromiso, podemos citar la Recomendación sobre la Ciencia y los investigadores científicos, de noviembre de 2017.

Y, como es lógico, a nivel estatal (y federal o autonómico en muchas ocasiones) existen una infinidad de normas jurídicas que regulan diversos aspectos de la bioética y que principian, en 
ocasiones, en contundentes declaraciones constitucionales sobre la dignidad humana que serán desigualmente desarrolladas a niveles normativos inferiores.

\subsubsection{La necesaria interrelación entre bioética y bioderecho.}

En cualquier caso, existe una íntima relación epistemológica (y metodológica también a mi juicio) entre bioética y bioderecho que hace que no puedan entenderse el uno sin la otra y viceversa. En palabras de Ángel Pelayo González-Torre una vez que el discurso ético sobre la actividad sanitaria sale del control de los profesionales de la salud, una vez que los temas bioéticos se convierten en cuestiones de debate social, y una vez que se manifiesta la necesidad de ejercer un control sobre las actividades sanitarias e investigadoras, va a ser el derecho el llamado a pronunciarse sobre lo que puede hacerse o no, y cómo, en el campo de las actuaciones sanitarias, tanto médicas como investigadoras (Pelayo, 2012, p. 21).

Puede afirmarse, con Romeo Casabona, que la bioética es hoy un claro ejemplo de aproximación a un objeto de estudio común multidisciplinar (para algunos incluso interdisciplinar), en el que confluyen diversas ciencias, además de la ética, con sus respectivas perspectivas y sus metodologías propias: la Medicina (en sus dimensiones tanto investigadora como clínica y asistencial), Biología (en sus dimensiones científica y tecnológica), diversos ámbitos de la Filosofía (además de la Ética), Teología, Psicología, Sociología, Economía, diversas tecnología, etc. (Romeo, 2011, p.3).

Cuestión distinta y por momentos compleja es la de la determinación de los ámbitos competenciales de cada disciplina, esto es, los límites o fronteras entre bioética y bioderecho.

Se trata, visto desde otro punto de vista, de una actualización de la antigua y controvertida reflexión sobre la frontera entre la moral y el derecho. Si a la ética -sobre la distinción entre ética y moral en este campo, vid. Albert Márquez, J. (2009, p. 75 y ss.)-, corresponde dilucidar entre lo "bueno" y lo "malo" para encaminar nuestras acciones hacia el bien, al derecho le compete determinar que está prohibido o permitido, y más exactamente a la justicia le incumbe determinar sobre la base del derecho qué es lo que objetivamente le corresponde a cada uno en cada caso concreto. Lo anterior no significa necesariamente que la relación entre ética y derecho sea absoluta y necesaria, pero sí, al menos (y siempre a nuestro juicio) que el derecho tenga como fundamento y límite ciertos valores, llamémosle éticos, incluso con independencia de que esos valores estén reflejados y sancionados en una norma de derecho positivo. Por otra parte, como destaca Aparisi, se podría subrayar el mayor interés del bioderecho por la perspectiva externa y por la dimensión de alteridad de las relaciones 
humanas, mientras que, en la bioética, ocuparía un papel central la noción de virtud (Aparisi, 2004, p.73)

La situación de las relaciones entre bioética y bioderecho la resume de manera muy gráfica Diego Gracia al afirmar que "el bioderecho sin bioética es ciego, y la bioética sin el bioderecho resulta vacía. Sin la bioética, el bioderecho correrá siempre el riego de caer «bajo mínimos»" (Gracia, 1989, p.576).

\section{3. ¿Bioderecho o biojurídica? El saber filosófico del derecho.}

Si analizamos ahora de modo especial la vertiente fundamentalmente jurídica de las cuestiones bioéticas, como hemos anticipado la propia denominación de la disciplina o disciplinas que se ocupan de ella no es pacífica. En España, el término más difundido es el de "bioderecho", que resulta ser una traducción directa de la expresión inglesa "biolaw", y relacionada también con "bioethics law". Con menos frecuencia se alude en España también a "biolegislación" o "biojurisprudencia" (Aparisi, 2004). El término "biojurídica", por su parte, procede de la doctrina italiana y es allí predominante.

Desde el punto de la filosofía del derecho, entendemos, con Aparisi a quien seguimos en este punto, que la distinción conceptual entre ambos términos sí puede tener relevancia. El bioderecho, en general, se ocuparía del estudio de las realidades bioéticas desde la perspectiva de la ciencia del derecho, esto es, desde el derecho positivo, y sería cultivada como disciplina autónoma sin dificultad por juristas que provienen precisamente de ramas específicas de la ciencia jurídica, como el derecho civil, penal, administrativo, constitucional, mercantil, etc.

Por su parte, la biojurídica estudiaría el mismo objeto (las realidades o fenómenos bioéticos: los diversos conflictos que surgen en el ámbito de las relaciones humanas como consecuencia de la incorporación de las nuevas tecnologías a las ciencias de la salud) desde el ámbito de la filosofía del derecho.

De este modo, la función de la biojurídica será, precisamente, la de justificar los principios, no morales, sino propiamente jurídicos, en los que se apoyaría el bioderecho o la biolegislación (Aparisi, 2004, p. 80). En la práctica, continua Aparisi, a la filosofía del derecho le compete un ámbito de trabajo aún por explorar: la elaboración de una biojurídica, ni moral, ni política, sino estrictamente jurídica.

En cualquier caso, la diferenciación entre bioética y bioderecho no es doctrinalmente pacífica, al menos entre la doctrina española. El Prof. Andrés Ollero, por su parte, identifica los dos términos porque entiende el bioderecho como "una nueva rama jurídica caracterizada por su 
atención al respeto y protección de la vida humana, desde la concepción a su final. Se la ha calificado en ocasiones, impropiamente, como «Biojurídica». La bioética es una rama de la ética, entendido este término como sustantivo y no como adjetivo; si llamamos «Derecho» al estudio de la regulación jurídica de diversos aspectos de la vida de la sociedad, parece lógico acudir a tal sustantivo y no a un adjetivo para identificar a la naciente disciplina" (Ollero, 2006, p. 19). Por su parte, Atienza parece posicionarse, aun indirectamente, por la tesis diferenciadora, al sostener que por ejemplo nos podemos referir al derecho civil -donde el término "derecho" se emplea como sustantivo- , para remitir a un a concreta rama del derecho; asimismo, podemos emplear la expresión "filosofía jurídica" -en la que por el contrario, el vocablo «jurídica» se utiliza como adjetivo-, para designar la reflexión totalizadora y crítica sobre el fenómeno jurídico (Atienza, 1984, p. 32).

La cuestión nominal o terminológica roza además a nuestro juicio, con la de la ubicación del saber concreto al que nos referimos y la de su jerarquía. Resulta imprescindible acudir es ese caso a la jerarquización de los saberes que realizara en su día Elías de Tejada y que también suscribía Lorca Navarrete. Así, para Elías de Tejada, dentro del saber razonado (esto es, aquel que no es evidentes ni revelado, y en el que interviene la razón humana como elemento definidor) se ubican el saber común, el técnico, el científico y el filosófico (Elías de Tejada, 1974, p.28). El saber científico se considera superior al técnico, y el filosófico a todos los demás; Lo propio ocurre en el ámbito del saber jurídico, en cuyo caso el saber superior es el filosófico jurídico, siendo saberes inferiores el saber jurídico científico y el jurídico técnico. Si adoptamos esta conceptualización, el bioderecho sería un tipo de saber técnico o científico, y la biojurídica ocuparía el predio de saber filosófico. La filosofía del derecho encuentra así, un nuevo campo de actuación para el que se encuentra no solo legitimada, sino también particularmente facultada para desempeñar un papel relevante en el razonamiento jurídico sobre la bioética.

En esta línea, Aparisi aboga por una biojurídica que aborde, entre otras, las siguientes cuestiones: el problema conceptual (contenido y límites de la biojurídica); la dimensión axiológica o valorativa (que se ocuparía del fundamento y legitimidad del bioderecho, buscando elaborar una biojurídica "ni moral ni política, sino estrictamente jurídica") y por último, le incumbe a la biojurídica abordar la cuestión relativa a la intersección entre el derecho y la realidad social (Aparisi, 2004, p. 86 y s.). 


\section{4. ¿Qué biojurídica, qué bioderecho? El problema de la fundamentación.}

Entendida así la biojurídica (o si se quiere, como Ollero, el bioderecho) como la reflexión sobre la bioética desde la filosofía jurídica, parece preciso fundamentarla epistemológicamente de modo que el término se refiera a una realidad más o menos uniforme y no dependa en exclusividad del hermeneuta al uso. Ocurre en este sentido que, dejando (inicialmente) al margen posturas extremadamente utilitaristas o de puro positivismo legalista, casi todos los autores consideran que la dignidad humana es ese principio apto para fundamentar el bioderecho. Ahora bien, no hay ni por asomo consenso en qué consiste exactamente esa idea de dignidad.

Incluso podemos apuntar, que se cuestiona incluso la necesidad de fundamentar el bioderecho, como se cuestiona hacerlo con los derechos humanos. Como es sabido, es muy citada la frase de Bobbio de que el problema de los derechos humanos no es fundamentarlos, sino realizarlos o protegerlos (Bobbio, 1982). Estimamos, con Robles, que ese puede ser el problema práctico de los derechos humanos, pero el problema teórico es el de su fundamentación, y que esta fundamentación teórica es necesaria por razones de tipo moral (pues no podemos defender ni realizar los derechos humanos si no estamos convencidos de su bondad moral, de que su implantación hace mejorar a los hombres y a la sociedad ser más justa); por razones de tipo lógico (porque es necesario determinar materialmente su contenido intrínseco); por razones de tipo teórico (indispensable en el caso de los juristas) y por último por razones pragmáticas (pues, como Robles señala, carece de sentido luchar por algo sin saber porque se lucha), (Robles, 1992, pp. 11-15). Estimamos que lo propio es predicable del bioderecho, que merece sin duda ser fundamentado de modo sólido en sede teórica para, entre otras cuestiones, que puede ser eficaz en la práctica.

El problema comienza, precisamente, al intentar conceptualizar la dignidad humana. Como Spaemann señala, "lo que la palabra dignidad quiere decir es difícil de comprender conceptualmente, porque indica una cualidad indefinible y simple" (Spaemann, 1989, p. 94). Aun así, Hervada la define en otro lugar como "la perfección o intensidad del ser que corresponde a la naturaleza humana y que se predica de la persona, en cuanto ésta es la realización existencial de la naturaleza humana" (Hervada, 1995, p. 449). Es sabido que Kant, en su Fundamentación de la metafísica de las costumbres observó que las personas "no son meros fines subjetivos, cuya existencia, como efecto de nuestra acción, tiene un valor para nosotros, sino que son fines objetivos, esto es, seres cuya existencia es en sí misma un fin, y un fin tal que en su lugar no puede ponerse ningún otro fin para el cual deberían servir ellas como medios (...) Los seres racionales se llaman personas porque su naturaleza los distingue 
ya como fines en sí mismos, esto es, como algo que no puede ser usado meramente como medio, y, por tanto limita en este sentido todo capricho (y es objeto de respeto)". (Kant, 1983, p. 83). Este concepto kantiano, a pesar de ser comúnmente aceptado tout court, merece alguna objeción importante.

Como recuerda Aparisi, lo cierto es que conviene matizar, (Aparisi, 2013, p. 208) que cualquier miembro de la especie humana, en razón de su dignidad ontológica, no es, en palabras de Spaemann, sólo "un fin en sí mismo para sí" (con un fundamento subjetivo) sino, un fin en sentido objetivo, por antonomasia por eso la dignidad no tiene su fundamento, en última instancia, en la autonomía personal o en el consenso social. El valor intrínseco de la dignidad ontológica se sitúa por encima de las normas jurídicas que se establezcan en una sociedad (Aparisi, 213, p. 209).

Es por ello por lo que entendemos que sólo desde una fundamentación ontológica fuerte, se puede defender en la praxis un concepto de dignidad humana hábil para adoptar las decisiones mejores y más justas en el caso concreto. En palabras de Ollero, la dignidad humana aparece como la realidad objetiva capaz de legitimar el consenso racional. Admitir su existencia obliga a asumir el condicionamiento global de toda realidad, aunque resulte más amplia; su búsqueda es lo que dará sentido al actual humano. Los imperativos de racionalidad son sólo un aspecto mínimo de la dimensión ética que la búsqueda jurídica ha de mantener de continuo para no perder su legitimación (Ollero, 1986, p.116). Esta fundamentación ontológica fuerte, como la hemos adjetivado, pasa por garantizar el respeto incondicionado y sin discriminación alguna, de todo ser humano, y en definitiva la igualdad y universalidad de los derechos humanos (Aparisi, 2013, p. 215).

En primer lugar, y aun que exceda el ámbito del presente trabajo, es necesario hacer nota que la dignidad humana, así entendida, es igualmente válida como fundamento de los derechos humanos, clave actual de conexión universal entre la ética y el derecho. No es que constituya la dignidad un derecho humano o un derecho fundamental, sino que más bien es la propia o la misma fundamentación de los derechos humanos.

Robles recuerda como la idea kantiana de dignidad posee dos aspectos que no son separables. Ad intra, la persona desde sí misma como valor, que se traduce en el respeto hacía sí misma y en la indisponibilidad de la propia persona, que en ningún caso puede transformarse en medio. Por eso la relación del hombre consigo mismo no es una relación de propiedad del yo sobre su vida y su cuerpo, sino una relación de obediencia al conjunto de deberes que derivan de la idea de humanidad. En segundo aspecto de la dignidad del hombre, es el aspecto ad extra y deriva del primero: consiste en el reconocimiento por parte de los 
otros de la dignidad que, como persona, les es inherente al hombre. Todo ser humano, independientemente de sus caracteres físicos, y psíquicos, independientemente, del momento de su formación biológica e independientemente de sus creencias y de su conducta, es un valor en sí mismo que, por tanto, no puede ser utilizado ni instrumentalizado transformándolo en objeto o en medio (Robles, 1992, p. 187-188).

Esta concepción otológica de la dignidad no es reciente. Santo Tomás, en la Suma Teológica, sostenía que "el término dignidad es algo absoluto y pertenece a la esencia" (Aquino, 2010, 731 y ss.) y afirmaba que "es evidente por sí misma cualquier proposición cuyo predicado pertenece a la esencia del sujeto" (Aquino, 2010, p. 411), esto es, que es evidente por sí mimo que todo ser humano posee dignidad, como una peculiar cualidad de su ser, como núcleo de su persona.

Por esto, el carácter ontológico de la dignidad humano implica, como hemos apuntado con anterioridad, que no pueda derivarse el fundamento de la dignidad hacia la autonomía del individuo ni hacia el consenso fáctico intersubjetivo. En ese caso, convertimos la dignidad en algo subjetivamente valioso, pero insuficiente (Aparisi, 2006, p. 172). Lo mismo se puede argumentar respecto del deslizamiento, tan evidente como reciente, del contenido de la dignidad humana hacia otro tipo de derechos, particularmente el derecho a la intimidad, como recurrentemente sentencia el Tribunal Europeo de Derechos Humanos, no sobre la base del art. 2 de Convenio de Roma (que protege el derecho de toda persona a la vida), sino partiendo de una interpretación extensa del artículo 8 del mismo Convenio, que protege el derecho a la intimidad en estos términos: "Derecho al respeto a la vida privada y familiar: 1 . Toda persona tiene derecho al respeto de su vida privada y familiar, de su domicilio y de su correspondencia. 2. No podrá haber injerencia de la autoridad en el ejercicio de este derecho, sino en tanto en cuanto esta injerencia esté prevista por ley y constituya una medida que, en una sociedad democrática, sea necearía parala seguridad nacional, la seguridad pública, el bienestar económico del país, la defensa del orden y prevención el delito, la protección de la salud o de la moral, o la protección de los derechos y las libertades de los demás". En este sentido, y por todas, se puede ejemplificar en el caso de Gross contra Suiza, resulto en sentencia de 14 de mayo de 2013, en el que se considera que "el deseo de la recurrente de que le sea facilitada una dosis de pentobarbital permitiéndole terminar con su vida forma parte de su derecho al respeto a la vida privada del artículo 8 de la Convención" (Case of Gross vs. Switzerland, $\mathrm{n}^{\circ}$ 67810/10, Judgment, Strasbourg, 14 may 2013).

Esta conceptualización de la protección del derecho a la vida (derecho derivado directamente de la dignidad humana, que considera a la vida humana como algo digno de protección 
integral) ha propiciado su interpretación extensiva hacia otros problemas jurídicos, como por ejemplo el aborto. Así, por ejemplo, en España, la Exposición de Motivos de la LO 2/2010, de 3 de marzo, de salud Sexual y Reproductiva e Interrupción Voluntaria del Embarazo (BOE de 4 de marzo de 2010) afirma textualmente que "la decisión de tener hijos y cuando tenerlos constituye uno de los asuntos más íntimos y personales que las personas afrontan a lo largo de sus vidas, que integra un ámbito esencial de la autodeterminación individual. Los poderes públicos están obligados a no interferir en este tipo de decisiones, pero, también, deben establecer las condiciones para que se adopten de forma libre y responsable, poniendo al alcance de quienes lo precisen servicios de atención sanitaria, asesoramiento o información. La protección de este ámbito de autonomía personal tiene una singular significación para la mujer, para quienes el embarazo y la maternidad son hechos que afectan profundamente a sus vidas en todos los sentidos".

Permítansenos los anteriores ejemplos porque en materia jurídica (y más aún en la ética) el tránsito de la teoría a la praxis no es baladí. Como Michel Sandel escribía sobre la filosofía platónica, con relación a la aristotélica, una filosofía a la que no rocen las sombras sobre la pared no será sino una utopía estéril, (Sandel, 2017, p. 40.) Acabamos de ver dos ejemplos, situados al final y al inicio de la vida, en los que un determinado concepto de dignidad humana (aún no nombrada expresamente) puede conducir a suprimir precisamente la vida al amparo de un derecho, el de la intimidad, que realmente no fue concebido principalmente para dilucidar estas cuestiones.

\section{Hacia un "bioderecho en acción" bajo la guía de una biojurídica valorativa.}

Quizá por ello se ha planteado también entre la doctrina (Albert, 2013, pp. 223 y ss.) la oportunidad de poner en práctica, junto a la "biolegislación" un llamado "bioderecho en acción" porque la protección de la vida se juega también, y decisivamente, en la praxis jurídica, en la interpretación y en el proceso de recreación del derecho que conduce a la solución del caso concreto. Se trataría pues de una visión amplia del bioderecho entendido como aquel obrar jurídico en el que se determina el derecho a la vida humana. En esta visión, cabría tanto la acción del legislador como la del resto de los operadores jurídicos, y de los ciudadanos (Albert, 2013, p. 231-233) pues, en definitiva, la mayoría de los conflictos biojurídicos contemporáneos dependen de cómo entendamos el lenguaje de los textos biojurídicos. Comenzado, podemos precisar, por el propio concepto de dignidad humana, del cual dependen todos los demás.

Por eso entendemos que el bioderecho debería de inspirarse en los mismos principios que desde finales del siglo pasado fundamentan la bioética. En 1974 el Congreso norteamericano constituyo una Comisión sobre investigaciones clínicas con personas que desconocían que 
fueron utilizadas como cobayas humanas. Cuatro años después, la National Commision for the protection of Human Subjets of Biomedical Behavioral Research, presentó el conocido Informe Beltmon, en el que se formulaban tres principios básicos de la bioética:

1ํ Principio de autonomía, o de respeto de la persona. Se trata, según el informe, de la exigencia de asegurar el efectivo respeto de la voluntad de participar o no en investigaciones clínicas experimentales. El propio informe ofrece directivas generales sobre el "consenso informado", o consentimiento informado (se entiende que libre y voluntario) por parte de la persona afectada.

2ำ Principio de beneficencia: Sus reglas complementarias, según el propio Informe, son: no producir daños (hoy en día se hace necesario clarificar la distinción entre mater y dejar morir, o entre suspender y abstenerse de tratamientos), maximizar las ventajas y minimizar los riesgos.

3 Principio de justicia: los riesgos y beneficios de la investigación médica se han de repartir con imparcialidad.

Estos principios se circunscribían, recordémoslo, al área de la experimentación médica por lo que pronto se planteó la búsqueda de criterios válidos para toda el área biomédica, cuyas bases se sentaron en la obra de Tom Beauchamp y James F. Childress Principles of Biomedical Ethics, de 1979. En ella, el aspecto negativo del principio de beneficencia ("no causar daños") se constituye en principio aparte, denominado "ausencia de daño" y que se sitúa en segundo lugar, después del de autonomía (Ciccione, 2006, 39 y ss.).

Aunque el "funcionamiento por principios", incluso con alguna variación -así por ejemplo, Gracia establece entre ellos una jerarquía justificada en la que sitúa en el primer puesto el principio de beneficencia y no el de autonomía- (Gracia, 1989, p.22) ha tenido un gran éxito en bioética, tampoco han faltado críticas, en cuanto a la posibilidad de que se abriera la puerta al relativismo moral, por lo que Sgreccia reclama una mayor fundamentación ontológica y antropológica de los mismos, sin la cual son estériles y confusos (Sgreccia, 2018, p. 181 y ss.).

En el ámbito jurídico, estimamos que del mismo modo que desde tiempos del derecho romano se tiene por pacífica la importancia y virtualidad de los tria iuris praecepta que Ulpiano llevó al Digesto -D. 1.1.10.1-, como principios jurídicos fundamentales (vivir honestamente, no dañar a nadie y dar a cada cual lo suyo) a los que debe acudir no solo el ciudadano y el legislador, sino también el jurista como intérprete de la norma, son igualmente predicables los principios 
de la bioética, fundados todos en la concepción ontológica de la dignidad humana y con especial relevancia del principio de justicia.

La aplicación concreta ("en acción", como se ha señalado) de las normas jurídicas que componen el bioderecho, encontrarían su fundamentación última en el principio de dignidad ontológica, y sus principios rectores en los de autonomía, beneficencia y justicia, pero en una idea de justicia, entendemos nosotros, más próxima al ideal aristotélico-tomista que al que se deriva de las actuales interpretaciones del concepto kantiano de autonomía personal. Por eso no creemos que sea posible deliberar sobre que sea lo justo o lo injusto sin deliberar previamente sobre que es lo bueno o lo malo, y sobre el significado de los bienes que la sociedad asigna. Sin embargo, para una justicia entendida al modo kantiano, o más modernamente como lo hace Rawls, (Rawls, 1997) lo que es debido (es decir lo que le corresponde a cada cual por serle justo en el cao concreto) precede a qué se tenga por un bien. Los principios de la justicia que definen nuestros deberes y derechos han de ser neutrales con respecto a las diversas y contrapuestas maneras de concebir la vida buena. Para llegar a la ley moral, sostiene Kant, debemos abstraernos de nuestros intereses y fines contingentes. Para deliberar sobre la justicia, mantiene Rawls, debemos dejar aparte nuestras metas, apegos, u maneras particulares de concebir qué cuenta como un bien. Ese es el motivo de que conciba la justicia tras el velo de la ignorancia (Sandel, 2017, p. 274). Por el contrario, desde una perspectiva aristotélica, teleológica y abierta a la naturaleza intrínsecamente relacional del hombre en sociedad y del derecho, los principios rectores de la justicia no pueden ni deben ser neutrales con respecto a la vida buena, y no cabe duda de que esta principia por la protección y defensa de la propia vida y de la dignidad humana por encima de cualesquiera otros tipos de consideraciones. No es posible, observa Ollero, la inocencia de ninguna propuesta metodológica (Ollero, 1989, p.15).

\section{CONCLUSIONES}

Los recientes avances en los ámbitos de la técnica y de la ciencia han dado lugar al surgimiento de nuevas cuestiones en la sociedad que hasta hace poco podrían parecer de ciencia ficción: desde la manipulación de gametos humanos hasta la gestación por sustitución con material genético ajeno, hasta la creación de órganos a través de células madre, o la misma clonación humana. En definitiva, se conforma un novedoso panorama no solo científico, sino abierto al debate social, en el que se cuestionan la bondad de estas técnicas y sus resultados. Evidentemente, esta situación no solo afecta a la medicina o a la biología, sino que se extiende a la ética, a la moral, a la teología, al derecho, a la sociología, a la economía, 
a la ecología, etc., configurando una situación de facto que requiere soluciones a los conflictos que se generan y a los que en un futuro se producirán.

Es por esto por lo que surgió a finales del pasado siglo una disciplina autónoma, la bioética, que pronto fue seguida, en el plano jurídico, del llamado bioderecho (entendido como conjunto de normas que tiene por objeto los diversos aspectos de lo que se ocupa la bioética). Pero un simple bioderecho de carácter analítico o descriptivo no justificaría a nuestro juicio su carácter de disciplina autónoma si no va acompañada de una reflexión axiológica sobre su fundamentación, su contenido, sus límites y sus fines. Esa es justo la razón de ser y el objeto de la biojurídica, disciplina que, aun teniendo también un marcado carácter interdisciplinar, reclama la presencia constante de la filosofía del derecho como saber superior de referencia. No obstante, ni la bioética, ni el bioderecho, ni la biojurídica tienen un significado definido si no se encuentran sólidamente fundamentadas. Entendemos que la dignidad humana, en su sentido ontológico, constituye el elemento fundamentador de estas tres disciplinas, y que, de él, a su vez, de derivan los principios rectores básicos de la bioética y del bioderecho.

Corresponde luego, dentro del ámbito propiamente jurídico, a los distintos operadores jurídicos determinar en cada caso que es lo justo en aplicación de las normas del bioderecho, y es en esa labor en la que han de tomar en consideración, como principios rectores que no deben ser sobrepasados ni violentados, los principios comúnmente admitidos de la bioética. La determinación del derecho no es fundamentalmente una ciencia, sino un arte que requiere un hábito, un ejercicio continuo, una constante y perenne voluntad de dar a cada cual lo suyo, y ocurre con la justicia algo parecido a lo que acontece con la idea de dignidad: podemos no saber exactamente en qué consiste siempre e invariablemente, pero también podemos llegar a ella cuando percibimos su negación, cuando observamos la injusticia o los actos indignos que comenten algunas personas.

Y ninguna norma jurídica, ni ningún acto humano pueden ser contrarios a la dignidad humana. Por eso, se ha hablado del "superconcepto de dignidad de la persona" (Ferreira da Cunha, 2013, 234).

\section{REFERENCIAS BIBLIOGRÁFICAS}


Albert Márquez, J.J. (2009). Marco bioético y jurídico en cuidados paliativos: el caso andaluz. En D. Medina y José J. Albert (Comps.) Bioética y Bioderecho. (75-89). Córdoba: Seminario de Filosofía del Derecho (SFD).

Albert Márquez, M. (2013/2ª $)$. ¿Hacia un bioderecho universal? Bioderecho en acción y funcionalización del valor de la vida humana. Cuadernos de Bioética, XIV, 223-237.

Aparisi Miralles, A. (2004/2aํ). Bioética, bioderecho y biojurídica. (Reflexiones desde la filosofía del derecho). Anuario de Filosofía del Derecho, 24, 63-84.

Aparisi Miralles, A. (2013/2 $\left.2^{\mathrm{a}}\right)$. El principio de la dignidad humana como fundamento de un bioderecho global. Cuadernos de Bioética, XXIV, 201-221.

Aparisi Miralles, A. (2006), Fundamento y Justificación de los Derechos Humanos, en Megías Quirós, J.J. (2006) (Coord.) Manual de Derechos Humanos. Los Derechos Humanos en el siglo XXI. (163-184). Navarra: Thomson Aranzadi.

Aquino, T. (2010). Suma Teológica, I. reimpr. 3롤., Madrid: BAC.

Atienza, M. (1984). Problemas abiertos en la Filosofía del Derecho. Doxa, (1), 29-34.

Bernard, J. (1994). La Bioética. Madrid: Debate.

Ciccone, L., (2006, 2 $2^{\underline{a}}$ ed.). Bioética. Historia, Principios. Cuestiones. Madrid: Palabra. Colección Pelícano.

Cunha, P. Ferreira de (2013). Repensar o Direito. Um manual de filosofía jurídica. Lisboa: Imprensa Nacional-Casa da Moeda

Elías de Tejada y Spínola, F., (1974). Tratado de filosofía del derecho. Tomo I. Sevilla: Publicaciones de la Universidad de Sevilla.

García Fernández, D. (2010). Una aproximación al Bioderecho. Anuario de Derechos Humanos. Nueva Época, 11, 203-224.

González R. Arnaiz, G. (2004), Bioética: Una aproximación desde la Filosofía Moral. En Junquera de Estéfani, R. Algunas cuestiones de bioética y su regulación jurídica (2360). Sevilla: Grupo Nacional de Editores.

Gracia, D., (1989). Fundamentos de Bioética. Madrid: Eudema.

Hervada, J., (1995). Lecciones propedéuticas de filosofía del derecho. Pamplona: Eunsa. 
Jonas, H., (1994). El principio de responsabilidad. Ensayo de una ética para la civilización tecnológica. Madrid: Círculo de Lectores. Junquera de Estéfani, R., (1998). Reproducción Asistida, Filosofía Ética y Filosofía Jurídica. Madrid: Tecnos.

Kant, I., (1983, $8^{\text {a }}$ ed.). Fundamentación de la metafísica de las costumbres. Madrid: Espasa Calpe.

Lewis, C.S. (2016). La abolición del hombre. Nashville, Tennessee: HarperCollins Español.

Medina Morales, D. (2009). La verdad no nos pertenece. En D. Medina y José J. Albert (Comps.) Bioética y Bioderecho. (7-14). Córdoba: Seminario de Filosofía del Derecho (SFD).

Megías Quirós, J.J. (2009) Naturaleza, ser humano y biotecnología. En D. Medina y José J. Albert (Comps.) Bioética y Bioderecho. (47-61). Córdoba: Seminario de Filosofía del Derecho (SFD).

Morelli, M., (2010). El concepto del bioderecho y los derechos humanos. Vida y Ética, Año 11, nำ1, 195-222.

Ollero Tassara, A. (1986). Derechos humanos y metodología jurídica. Madrid: Centro de Estudios Constitucionales.

Ollero Tassara, A. (2006). Bioderecho. Entre la vida y la muerte. Navarra: Thompson Aranzadi.

Pelayo González-Torre, A., (2012). Bioética, bioderecho y biopolítica. Una aproximación desde España. Criterio Jurídico Garantista. (Año 3, N.ำ6), 12-35.

Porras del Corral, M., (1996). Biotecnología, Derecho y Derechos Humanos. Córdoba: Cajasur Publicaciones.

Rawls, J. (1997). Teoría de la Justicia. Madrid: Fondo de Cultura Económica de España.

Reich, W. (Coord.) (1995). Encyclopedia of Bioethics, New York: Macmillan.

Robles, G. (1992). Los derechos fundamentales y la ética en la Sociedad actual. Madrid: Civitas.

Romeo Casabona, C.M. (2017). El Bioderecho y la Bioética, un largo camino en común. Revista Iberoamericana de Bioética, (3), 1-16.

Sandel, M. (2017, 3ํㅡㄹ ed.). Justicia ¿Hacemos lo que debemos? Barcelona: Debate. 
Schaefer Rivabem, F. (2017). Bioderecho: ¿una disciplina autónoma? Revista de Bioética, (25), 282-289.

Sgreccia, E. (2018). Manual de Bioética. I Fundamentos y ética biomédica. Madrid: BAC:

Spaemann, R. (1988). Lo natural y lo racional. Ensayos de antropología. Sobre el concepto de la dignidad humana. (89-123) Madrid: Rialp. 